\title{
Strategi Manajemen Komunikasi Mempertahankan RePUtasi
}

\author{
${ }^{1}$ Gita Widiasanty, ${ }^{2}$ Irwansyah \\ Sekolah Tinggi Ilmu Komunikasi InterStudi, Jl. Wijaya II/62 Kebayoran Baru, Jakarta Selatan \\ e-mail: gwidyashanty@yahoo.comdandr.irwansyah.ma@gmail.com
}

\begin{abstract}
Abstrak.Hiburan merupakan hal yang dimaksudkan untuk menghibur atau menarik orang, salah satu bentuk hiburan adalah musik. Bermain musik dapat dilakukan secara bersama membentuk sebuah kelompok musik yang lebih dikenal dengan band. Di Indonesia banyak band pendatang baru, walaupun demikian terdapat band yang sudah berdiri lama namun masih produktif mengeluarkan album hingga sekarang. Kahitna adalah grup musik asal Bandung yang dibentuk 24 Juni 1986, merupakan salah satu band di Indonesia yang mempunyai kekuatan merata di semua lini ditandai dengan aktivitas para personilnya. Walau lintasan trend dan jaman telah berlalu namun Kahitna masih berdiri tegak dan tetap dengan notasi indah penuh romantisme tingkat tinggi, sebuah kekuatan yang selalu hadir dalam lagu-lagu Kahitna, senjata itulah yang membuat Kahitna bertahan sampai saat ini. Alasan pemilihan topik ini karena Kahitna dapat bertahan eksistensinya sampai saat ini, walaupun terdapat band-band di Indonesia yang usia terbentuknya sama dengan Kahitna yaitu Java Jive, Kla Project, dan Dewa19 yang sama-sama memiliki karya-karya yang baik, reputasi yang baik dan memiliki usia keemasan yang lama, namun berdasarkan fakta, Kahitna adalah band yang masih bertahan hingga saat ini dengan mengeluarkan album-album dan mengadakan show secara kontinyu. Bertolak dari permasalahan tentang pentingnya strategi komunikasi dalam mempertahankan reputasi Kahitna, maka penelitian ini dilakukan untuk mengetahui lebih dalam cara penggunaan strategi manajemen komunikasi dalam manajemen artis Kahitna sehingga popularitasnya konsisten sampai sekarang.
\end{abstract}

Kata Kunci: hiburan musik - kekuatan bertahan - reputasi komunikasi.

\section{Pendahuluan}

\section{Latar Belakang}

Kahitna adalah grup musik asal Bandung yang dibentuk 24 Juni 1986, merupakan salah satu band di Indonesia yang mempunyai kekuatan merata di semua lini ditandai dengan aktivitas para personilnya yaitu Yovie Widianto (keyboard), Hedi Yunus (vokal), Carlo Saba (vokal), Mario Ginanjar (vokal), Bambang Purwono (keyboard), Harry Suhardirman (perkusi), Budiana Nugraha (drum), Dody Isnaini (bass), dan Andrie Bayuadjie (gitar).

Walau lintasan trend dan jaman telah berlalu namun Kahitna masih berdiri tegak dan tetap dengan notasi indah penuh romantisme tingkat tinggi, sebuah kekuatan yang selalu hadir dalam lagu-lagu Kahitna, senjata itulah yang membuat Kahitna bertahan sampai saat ini. Dengan menggunakan strategi komunikasi harus mampu menunjukkan bagaimana operasionalnya secara praktis yang harus dipraktekkan. Strategi pada hakikatnya adalah perencanaan (planning) dan manajemen untuk mencapai suatu tujuan. Strategi komunikasi yang merupakan paduanpaduan rencana komunikasi dan manjemen komunikasi untuk mencapai tujuan yang telah ditetapkan (Amri, 2010).

Alasan pemilihan topik ini karena Kahitna adalah band nomor satu di Indonesia. Menurut Roni Waluya (mantan vokalis Kahitna), Kahitna 
adalah band nomor satu di Indonesia, semenjak Roni Waluya ada di Kahitna nomor satu, begitu keluar semakin nomor satu. Hal yang menjadikan Kahitna sebagai band nomor satu tidak semata mengacu pada catatan gemilang "masa lalu" namun keberadaannya hingga kini menjadi kegemilangan terbesar mereka. Ukuran-ukuran yang digunakan Kahitna untuk menilai kualitas dan perjalanan kreativitas mereka tidak sepenuhnya identik dengan parameter-parameter yang saat ini ramai digunakan (Wardhana, 31 Juli 2010).

Alasan pemilihan topik ini karena Kahitna dapat bertahan eksistensinya sampai saat ini, walaupun terdapat band-band di Indonesia yang usia terbentuknya sama dengan Kahitna yaitu Java Jive, KLa Project, dan Dewa 19 sama-sama memiliki karya-karya yang baik, reputasi yang baik dan memiliki usia keemasan yang lama, namun berdasarkan fakta, Kahitna adalah band yang masih bertahan hingga saat ini dengan mengeluarkan albumalbum dan mengadakan show secara kontinyu.

Dengan membandingkan antara Kahitna dengan Java Jive, KLa Project dan Dewa 19, dapat terlihat bahwa Kahitna adalah band yang paling bertahan reputasinya, karena Kahitna dari awal berdirinya yaitu tahun 1986 sampai dengan saat ini tetap berkarya dan tidak pernah vakum walaupun pernah mengalami pergantian personil.

Bertolak dari permasalahan tentang pentingnya strategi komunikasi dalam mempertahankan reputasi Kahitna, maka penelitian ini dilakukan untuk mengetahui cara penggunaan strategi manajemen komunikasi dalam manajemen artis Kahitna sehingga popularitasnya konsisten sekarang.

\section{Landasan Konsep}

Komunikasi organisasi adalah pengiriman dan penerimaan berbagai pesan organisasi di dalam kelompok formal maupun informal dari suatu organisasi (Prakosa, 2007).

Komunikasi organisasi dapat bersifat formal dan informal. Komunikasi formal adalah komunikasi yang disetujui oleh organisasi itu sendiri dan sifatnya berorientasi kepentingan organisasi, isinya berupa cara kerja di dalam organisasi, produktivitas, dan berbagai pekerjaan yang harus dilakukan dalam organisasi, sedangkan komunikasi informal adalah komunikasi yang disetujui secara sosial, orientasinya bukan pada organisasi, tetapi lebih kepada anggotanya secara individual (Wiryanto, 2004: 54-55).

Komunikasi organisasi

dipandang sebagai proses mengumpulkan, memproses, menyimpan, dan menyebarkan informasi di antara unit-unit organisasi yang memungkinkan sistem komunikasi organisasi berfungsi secara efektif (Romli, 2010).

Barry Cushway dan Derek Lodge (dalam Panuju, 2001) menggambarkan fungsi komunikasi dalam organisasi sebagai pembentuk iklim organisasi yang menggambarkan suasana kerja organisasi atau sejumlah keseluruhan perasaan dan sikap orang-orang yang bekerja di dalam organisasi (Panuju, 2001: 1-4).

\section{Metodologi Penelitian}

Metodologi dalam penelitian ini merupakan pendekatan kualitatif deskriptif yang menggambarkan, meringkaskan berbagai kondisi, situasi atau berbagai variabel yang mengkaji "Strategi Komunikasi Mempertahankan Reputasi Kahitna" karena meneliti halhal bersifat khusus, memiliki makna 
historis, membuat penilaian etis dan estetis atas fenomena komunikasi spesifik untuk mencari dan memperoleh informasi mendalam dan sasaran penelitiannya terbatas, tetapi dengan keterbatasan sasaran yang ada digali sebanyak mungkin data mengenai sasaran penelitian (Moleong, 1989: 29).

Strategi dalam penelitian ini menggunakan studi kasus manajemen artis grup band Kahitna (Moleong, 1989: 87) dengan cara observasi tak berstruktur yang berguna untuk menjelaskan, memberikan dan merinci gejala yang terjadi (Rakhmat, 1989: 115-119).

Dalam penelitian ini yang menjadi informan adalah yang mewakili manajemen Kahitna dan personil Kahitna, terdiri dari 9 (Sembilan) orang personil Kahitna, 5 (lima) orang manajemen Kahitna dan 2 (dua) orang personal manager Kahitna.

Wawancara dilakukan secara mendalam (depth interviews) dengan pedoman wawancara (interview guide) yang dilakukan secara terbuka untuk memperoleh data, pelaksanaannya dilakukan dengan melakukan tatap muka dengan manajer Kahitna maupun personil Kahitna (Moleong, 2002).

\section{Hasil dan Pembahasan}

dunia Perubahan zaman dan trend di menenggelamkan Kahitna, hingga kini Kahitna tetap berhasil dengan baik memadukan unsur jazz fusion, pop hingga etnik dalam musiknya. Meskipun mengalami beberapa pergeseran dalam bermusik, perubahan tersebut tidak merubah karakter dan identitas Kahitna (Wardhana, 31 Juli 2010). Konsep musik yang diusung Kahitna adalah basic jazz yang kemudian pada perkembangannya memadukan semua unsur musik yang ada seperti pop.

Kahitna dapat dikategorikan sebagai organisasi formal, karena ada sistem manajerial dan pembagian kerja.
Kahitna dapat menjaga eksistensinya di dunia hiburan sehingga dapat bertahan selama 32 tahun, sejak berdirinya Kahitna tidak penah absen mengeluarkan album. Begitu pula dengan personil Kahitna yang jarang berganti-ganti. Kahitna tidak pernah menghilang di dunia musik Indonesia, itulah yang Kahitna jaga agar tetap eksis. Cara mempertahankan eksistensi tersebut adalah dengan mengadakan komunikasi yang baik, menjaga image, selalu berprestasi dan tidak berhenti berkarya.

Segmentasi Kahitna terdiri dari usia remaja sampai dewasa baik laki-laki maupun perempuan, dengan demikian Kahitna menciptakan lagu yang bahasanya indah dan mudah dimengerti, sehingga dapat diterima oleh seluruh pencinta musik Kahitna sepanjang masa. Adapun band yang menjadi pembanding Kahitna yaitu Java Jive yang didirikan di Bandung, Jawa Barat tahun 1993, beranggotakan Capung, Noey, Tony, Edwin, Fatur, dan Danny. Java Jive sudah mengeluarkan 8 (delapan) album dan beberapa single. Pada September 2013, album ke delapan yang berjudul Java Jive 20 Teman Sehati dirilis. Setelah itu Java Jive vakum, kemudian tahun 2017 mengeluarkan single 'Dansa Yo Dansa' yang merupakan lagu daur ulang musisi Titiek Puspa (liputan6.com 22 Des 2017, 10:10 WIB). Saat ini usia Java Jive berusia 25 tahun dengan personil yang tidak pernah berubah.

Selain Java Jive, band pembanding Kahitna yaitu Kla yang dibentuk oleh Katon, Lilo, Adi, dan Ari pada tahun 1988 didaerah Tebet, Jakarta. Tahun 2003, Kla memutuskan untuk menambah tiga orang personil baru, yaitu Erwin Prasetya, Yoel Vaidan, Hari Goro. Nama mereka pun berubah menjadi Nu KLa. Tidak lama setelah itu, Katon Bagaskara menyatakan bahwa $\mathrm{Nu}$ Kla berganti nama kembali menjadi Kla 
Project, karena sulitnya mengubah citra Kla yang lama menjadi baru (Laksmi, 2010).

Selain Kla, Dewa 19 merupakan grup musik pembanding Kahitna yang dibentuk tahun 1986 di Surabaya, kemudian hijrah ke Jakarta dan merilis album pertama tahun 1992 dibawah label Team Records. Dewa 19 beberapa kali mengalami pergantian personil dan formasi terakhirnya sebelum dibubarkan pada tahun 2011 yaitu Ahmad Dhani (keyboard), Andra Junaidi (gitar), Once Mekel (vokal), Yuke Sampurna (bass) dan Agung Yudha (Hakam, 2012).

Dengan membandingkan antara Kahitna dengan Java Jive, Kla Project dan Dewa 19, dapat terlihat bahwa Kahitna adalah band yang paling bertahan reputasinya, karena Kahitna dari awal berdirinya yaitu tahun 1986 sampai dengan saat ini (2018) tetap berkarya dan tidak pernah vakum walaupun pernah mengalami pergantian personil. Kahitna masih tetap berdiri dan mengeluarkan album secara konsisten dengan personil yang sudah tidak pernah berganti formasi sejak Roni Waluya keluar dan digantikan oleh Mario Ginanjar. Kahitna dengan lagu-lagunya disukai oleh berbagai lapisan masyarakat dan semua golongan usia selama dua dekade. Bagi Kahitna, ukuran pertama yang harus diingat adalah keberhasilan selaku band yang mampu menjaga wibawa sebagai pelantun lagu cinta terbaik selama dua dekade. Jika sekedar bertahan mungkin banyak band atau penyanyi yang mampu melakukannya, Kahitna bukan sekedar bertahan namun meyakinkan melewati perubahan zaman dengan hits-hits baru yang berbeda di setiap albumnya.

Segala informasi yang berkaitan dengan Kahitna antara lain saat dikeluarkannya album terbaru Kahitna, jadwal show, kegiatan di luar show maupun sisi humanis personil Kahitna berfungsi untuk mempertahankan eksistensi Kahitna di tengah-tengah pencinta musik Indonesia. Media merupakan media partner Kahitna, baik media cetak, media elektronik maupun media sosial, karena media merupakan senjata andalan dalam berpromosi, dengan media Kahitna dapat dikenal oleh masyarakat, oleh karena itu Kahitna sangat menjaga hubungan baik dengan media.

Profesi artis seperti grup band Kahitna sangat perlu mendapatkan saran, petunjuk, nasihat, arahan dari manajemen atau manajer artis dalam rangka kemajuan dan pengembangan karirnya (Yulistiani, 2009). Pengembangan yang dilakukan Kahitna merupakan bentuk kompromi cerdas mereka, karena tetap mantap dengan musiknya tanpa terbawa hasrat membuat karya yang sekedar populer namun minim kualitas. Kahitna menginginkan agar musik Indonesia dipenuhi beragam warna, karena hasrat membuat lagu yang sekedar mengikuti trend akan mengantarkan masyarakat pada kejenuhan. Itulah sebabnya hingga kini lagu-lagu Kahitna selalu dikenang dan mendapat tempat di hati penikmat musik, karena Kahitna selalu hadir istimewa dengan warna musik khas (Wardhana,31 Juli 2010).

Kahitna menggunakan komunikasi dua arah, dimana terjadi proses komunikasi secara langsung dan ada feedback secara langsung antara manajemen Kahitna dengan Kahitna, antara sesama personil Kahitna, antara manajemen Kahitna dengan crew, salah satunya adalah melalui grup pada Whatsapp. Untuk menjaga kebersamaan, Kahitna selalu mengadakan kegiatan bersama di luar musik, misalnya ibadah bersama, olah raga bersama, makan bersama dan hal lainnya. Tujuannya adalah untuk lebih mempererat tali persaudaraan Kahitna yang sudah seperti 
sebuah keluarga, dengan demikian selalu terjaga keakraban dan kekompakan, sehingga tidak sulit bagi Kahitna untuk bekerja sama dalam berkarir di Industri musik.

Kahitna berkomunikasi dengan penggemar melalui social media instagram, twitter dan facebook, segala sesuatu dapat dikomunikasikan pada social media tersebut, sehingga para penggemar lebih bebas mengekspresikan dirinya dan mengemukakan pendapatnya terhadap Kahitna, sedangkan bentuk pesan yang dibuat Kahitna agar musik yang telah dirilis dapat lebih diterima masyarakat harus positif.

Selain itu, Kahitna memiliki sebuah organisasi pencinta musiknya yang diberi nama "Soulmate", cara mengkoordinasi Soulmate Kahitna yaitu ada koordinator yang bertanggung jawab terhadap organisasi tersebut. Dampak strategi komunikasi tersebut adalah Kahitna semakin kenal dengan penikmat musiknya, karena dalam wadah tersebut selain dapat sharing dalam hal musik, juga dapat sharing dalam segala hal termasuk mengadakan kegiatan sosial bersama Kahitna, sehingga ada kedekatan antara Kahitna dengan para pencinta musiknya.

\section{Strategi}

Kahitna

mempertahankan reputasi yaitu dengan membangun prestasi, solidaritas dan kedisiplinan. Kahitna telah meraih beberapa prestasi di tingkat international maupun national, dengan prestasi yang telah diraih tersebut maka menjadikan Kahitna semakin memiliki kredibilitas di dunia hiburan khususnya musik. Dengan solidaritas segala hal yang telah direncanakan akan berjalan dengan lancar karena mengikuti prosedur yang telah direncanakan dalam suatu program. Di samping itu, Kahitna menjaga kualitas vokal, karena ujung tombak Kahitna terletak pada kualitas vokalnya, dengan kualitas vokal yang baik maka lagu-lagu yang dibawakannya berkualitas baik dan menjadikan sebuah prestasi bagi Kahitna. Kahitna juga menjaga penampilan baik ketika show maupun sehari-hari menjaga kekompakan di antara sesama personil Kahitna demi menjaga reputasi.

Kahitna menggunakan prinsipprinsip kerja sama baik internal maupun eksternal. Kerjasama antara Kahitna dengan manajemennya, kerjasama Kahitna dengan produser dan label rekaman, kerjasama Kahitna dengan stasiun TV, kerjasama antara Kahitna dengan stasiun radio. Kahitna juga bekerja sama antar personil dalam keluarga selain dalam grup. Dalam proses rekaman, Kahitna memilih produser yang memiliki visi dan misi yang sama. Dalam pendistribusian album Kahitna bekerja sama dengan label rekaman karena sudah memiliki channel-channel distribusi. Selain itu, Kahitna dan manajemen melakukan direct selling langsung menjual kepada penggemar, salah satunya dengan cara menerima pesanan dari fans-fans Kahitna.

Strategi komunikasi manajemen Kahitna dalam berpromosi adalah melalui media, antara lain media sosial, media cetak dan media elektronik. Market Kahitna dalam mempromosikan albumnya terbagi dalam beberapa segmentasi. Dalam promo album Kahitna menggunakan semua tools promosi, baik yang tradisional, modern maupun elektronik.

Pihak yang terkait dengan Kahitna adalah promotor, EO (Event Organizer), media, penggemar dan perusahaan-perusahaan yang membutuhkan jasa artis untuk menyampaikan produknya. Pertimbangan dalam menentukan dan memilih pihak-pihak terkait tersebut yaitu harus yang sesuai dengan musik dan image Kahitna. Event organizer merupakan kepanjangan tangan dari Kahitna dalam hal pertunjukkan, bintang 
tamu dalam suatu acara, launching produk maupun ulang tahun, event organizer sebagai pihak penyelenggara acara yang menetukan konsep acara yang harus diikuti oleh Kahitna.

Kahitna memiliki suatu bentuk pengarahan yang bukan merupakan hal yang sulit, karena Kahitna sudah menjadi sebuah keluarga dan mempunyai solidaritas. Satuan pengarahan pada manajemen Kahitna dipusatkan pada manajemen yang membuat satuan program yang akan disampaikan. Bagi Kahitna, peran manajemen artis sangat penting demi kemajuan karier dan saling support, karena seorang artis atau sebuah grup tidak dapat berdiri sendiri tanpa seorang manajer atau manajemen artis, karena manajemen yang mengatur segala kegiatan artis dari awal hingga akhir.

Manajemen Kahitna menggunakan sistem teamwork (kerja team) dalam melaksanakan semua pekerjaannya, dengan demikian segala bentuk pekerjaan tidak dikerjakan oleh sendiri, melainkan bersama-sama dalam team, dengan menggunakan prinsip solidaritas, transparansi, keadilan dan kejujuran agar segala sesuatunya dapat dikerjakan dengan lancar dan mendapatkan hasil yang maksimal. Kesatuan perintah dalam manajemen Kahitna terdapat pada leader yaitu Yovie Widianto.

Manajemen Kahitna

menciptakan ketertiban dalam setiap aktifitasnya dengan cara pembagian tugas, baik manajemen, personil Kahitna maupun crew memiliki tugas dan tanggung jawab yang harus dilakukan, dengan demikian segala sesuatunya terkoordinasi, sehingga tidak ada simpang siur tugas dan segalanya akan tertib apabila sudah ada pembagian tugas dan dilaksanakan dengan baik.

Dalam manajemen Kahitna, hal yang diutamakan untuk menjaga stabilitas yaitu dengan mengatur semua jadwal, sehingga ada keteraturan dalam melaksanakan semua kegiatan yang telah direncanakan. Jadwal yang telah diprogramkan pelaksanaannya disertai dengan kedisiplinan dan tanggung jawab serta bersikap dewasa dengan tujuan agar segalanya dapat dilaksanakan dengan baik sesuai dengan rencana.

Stabilitas Kahitna dibentuk dengan cara mengatur semua jadwal show, rekaman maupun pembuatan album, sehingga dapat memelihara stabilitas jadwal Kahitna, begitu pula dengan jadwal pembuatan album yang dilakukan setiap dua tahun, tujuannya agar pencinta musik Indonesia dapat menikmati musik Kahitna dalam waktu yang cukup, sehingga keberadaan Kahitna selalu terjaga reputasinya. Cara mempertahankan stabilitas tersebut adalah dengan mengatur jadwal berdasarkan kesepakatan dengan semua pihak, baik antara manajemen dengan personil Kahitna, maupun antara manajemen Kahitna dengan pihak-pihak terkait.

Sebagian personil Kahitna memiliki personal manager yang mamanajeri perorangan, Hedi Yunus dimanajeri oleh Hanief Yuhadian dan Mario Ginanjar dimanajeri oleh Nico. Personal manager tersebut mengatur kegiatan masing-masing personil Kahitna dan bekerja sama dengan semua pihak yang berhubungan dengan personil Kahitna, yaitu manajemen Kahitna, media dan penggemar untuk kelancaran karier masing-masing personil Kahitna. Personal manager juga memberikan arahan kepada personil Kahitna agar selalu profesional dalam pekerjaan dan bersikap ramah terhadap penggemar, karena semuanya berpengaruh terhadap kelancaran pekerjaan dan reputasi baik.

Nama baik Kahitna sangat berpengaruh untuk kelangsungan 
kariernya, dengan demikian Kahitna dapat mengenal politikus, keliling dunia, show di Asia, Eropa, bahkan sampai ke Amerika dan mengetahui banyak hal.

Kahitna memiliki peran dalam industri musik Indonesia dengan mengeluarkan sepuluh album dan eksis selama 32 tahun. Menyanyi bagi Kahitna merupakan sebuah hobi untuk menghibur diri sendiri maupun orang lain. Bagi Kahitna turut andil mengembangkan industri musik sangat penting, karena salah satu tujuan Kahitna yaitu ingin memajukan industri musik di Indonesia.

\section{Kesimpulan}

Strategi manajemen komunikasi grup musik dalam mempertahankan reputasi yaitu menjaga eksistensi dengan prestasi, tidak berhenti berkarya, menjaga kedisiplinan, mengadakan komunikasi yang baik antara sesama personil, manajemen artis dan pencinta musiknya serta memiliki visi dan misi memajukan musik Indonesia.

Dalam mengatur segala kegiatannya, grup musik memerlukan manajemen artis yang mengatur hak dan kewajiban para personilnya, membuat pembagian kerja maupun menjalin kerjasama dengan semua pihak berkaitan dengan kontrak, rekaman, show dan semua hal yang menyangkut kegiatan grup musik. Syarat manajer grup musik yaitu harus capable, mengetahui tentang grup musik yang dimanajeri, memiliki kemampuan manajerial dan memberikan dukungan terhadap grup musik dengan baik.

Segala hal yang berkaitan dengan grup musik dibuat oleh manajemen, kemudian disampaikan kepada personil grup musik tersebut, manajemen grup musik menggunakan komunikasi kekeluargaan dalam menjalankan segala sesuatunya dengan penuh tanggung jawab.
Dalam mempertahankan reputasi selain menggunakan manajemen komunikasi kekeluargaan didukung oleh kecanggihan teknologi whatsapp messanger untuk mempermudah komunikasi grup musik dengan manajemen, sedangkan social media instagram, facebook dan twitter digunakan untuk mempermudah komunikasi grup musik dengan masyarakat, sehingga masyarakat dapat mengekspresikan kata-kata tanpa filter untuk evaluasi grup musik.

\section{Daftar Pustaka}

Moleong, Lexy. 1989. Metode Penelitian Kualitatif. Bandung: PT. Remaja Rosdakarya.

Moleong, Lexy. 2002. Metode Penelitian Kualitatif. Bandung: PT. Remaja Rosdakarya.

Amri, Choir. 2010. Strategi komunikasi. www.google.com.5 Juni 2011.

Hakam, Arifin. 2012. Dewa 19. www.arifinhakam.wordpress.com. 1 Juli 2012.

Laksmi, Ayu. 2010. Kla Project Dengan lagu sepanjang Masa. www.ayulaksmi.blogspot.com . 28 Maret 2010.

Wardhana, Hendra. 2010. Alasan Mengapa Kahitna Menjadi Band Nomor 1. www.google.com . 31 Juli 2010.

Yulistiani, Indriati. 2009. Manajemen Artis. www.google.com . 31 Oktober 2009.

Simbolon, Huyogo. 2017. Java Jive Tak Gonta Ganti Personel Selama 24 Tahun. 22 Des 2017, 10:10 WIB. Liputan6.com. 
80 Gita Widiasanty., et al.

INTER KOMUNIKA Jurnal Komunikasi 